\title{
Variation in reoperation after colorectal surgery in England as an indicator of surgical performance: retrospective analysis of Hospital Episode Statistics
}

\author{
Elaine M Burns clinical research fellow ${ }^{1}$, Alex Bottle lecturer in medical statistics ${ }^{2}$, Paul Aylin clinical \\ reader in epidemiology and public heath ${ }^{2}$, Ara Darzi professor of surgery ${ }^{1}, \mathrm{R}$ John Nicholls professor \\ of surgery ${ }^{1}$, Omar Faiz senior lecturer and honorary consultant colorectal surgeon ${ }^{1}$
}

'Department of Surgery, Imperial College, St Mary's Hospital, London W21NY, UK; ${ }^{2}$ Dr Foster Unit, Department of Primary Care and Public Health, School of Public Health, Imperial College, London EC1A 9LA

\begin{abstract}
Objective To describe national reoperation rates after elective and emergency colorectal resection and to assess the feasibility of using reoperation as a quality indicator derived from routinely collected data in England.
\end{abstract}

Design Retrospective observational study of Hospital Episode Statistics (HES) data.

Setting HES dataset, an administrative dataset covering the entire English National Health Service.

Participants All patients undergoing a primary colorectal resection in England between 2000 and 2008.

Main outcome measures Reoperation after colorectal resection, defined as any reoperation for an intra-abdominal procedure or wound complication within 28 days of surgery on the index or subsequent admission to hospital.

Results The national reoperation rate was 6.5\% (15 986/246 469). A large degree of variation was identified among institutions and surgeons. Even among institutions and surgical teams with high caseloads, threefold and fivefold differences in reoperation rates were observed between the highest and lowest performing trusts and surgeons. Of the NHS trusts studied, $14.1 \%(22 / 156)$ had adjusted reoperation rates above the upper $99.8 \%$ control limit. Factors independently associated with higher risk of reoperation were diagnosis of inflammatory bowel disease (odds ratio $1.33(95 \% \mathrm{Cl} 1.24$ to 1.42$), \mathrm{P}<0.001)$, presence of multiple comorbidity (odds ratio 1.34 (1.29 to 1.39), $\mathrm{P}<0.001$ ), social deprivation (1.14 (1.08 to 1.20 ) for most deprived, $\mathrm{P}<0.001)$, male sex (1.33 (1.29 to 1.38), $P<0.001$ ), rectal resection (1.63 (1.56 to 1.71), $\mathrm{P}<0.001$ ), laparoscopic surgery (1.11 (1.03 to 1.20), $\mathrm{P}=0.006)$, and emergency admission (1.21 (1.17 to 1.26$), \mathrm{P}<0.001)$.

Conclusions There is large variation in reoperation after colorectal surgery between hospitals and surgeons in England. If data accuracy can be assured, reoperation may allow performance to be checked against national standards from current routinely collected data, alongside other indicators such as mortality.

\section{Introduction}

Colorectal surgery is associated with sizeable morbidity ${ }^{1}$ and, for emergency surgery, considerable mortality. ${ }^{2}$ There is considerable variation between individuals and institutions in colorectal surgical practice and outcome. ${ }^{3-5}$ Such variability is increasingly unacceptable to clinicians, healthcare managers, commissioners, and patients. Describing this variation in performance is an important first step to allow quality assessment and subsequent improvement. If we want to eliminate variation in surgical practice and improve standards we need specific indicators that reflect discrete parts of the patient journey. Postoperative mortality is currently one of the most widely recognised indicators of quality. ${ }^{5}$ However, in isolation, the use of mortality as a quality marker is limited. For elective surgery, postoperative death is rare, making it an insensitive alert to poor performance and requiring many cases before meaningful outliers can be identified. Furthermore, common definitions do not discriminate between all deaths and those that are potentially preventable. Finally, many failures in care do not always lead to death. Therefore, in addition to mortality, a range of indicators that offer an insight into genuine quality deficiencies among providers is required.

Postoperative reoperation has been suggested as a useful quality marker in the United States for general surgery ${ }^{6}$ and more recently for colorectal surgery. ${ }^{78}$ Reoperations after colorectal surgery are undertaken mostly for surgical morbidity such as postoperative bleeding or anastomotic leaks. Reoperation is associated with poor clinical outcome, including higher risk of early death and local recurrence as well as poorer overall survival. ${ }^{9}$ Reoperation, when taken alongside other accepted 
indicators such as mortality, potentially offers a sensitive and relevant marker of surgical quality. For a quality indicator to be usable there must be data available from which it can be measured. In the United Kingdom, nationwide administrative data that include all patients admitted to National Health Service (NHS) hospitals are collected. The availability and comprehensive coverage of these datasets make them an attractive potential source for measuring performance.

This study aims to describe national reoperation rates after colorectal resection and to investigate the feasibility of using reoperation rate as a quality indicator derived from routinely collected data.

\section{Method \\ Hospital Episode Statistics}

A description of the Hospital Episode Statistics (HES) database has been published previously.$^{10}$ It is an administrative dataset that collates information on all NHS and private patients admitted to NHS hospitals in England. Each admission contains a primary diagnosis and now up to 19 secondary diagnoses, categorised according to ICD-10 (international classification of diseases, 10th revision), and up to 24 procedure fields coded using OPCS-4 (Office of Population Censuses and Surveys Classification of Surgical Operations and Procedures 4th revision). The Charlson comorbidity index derived from the secondary diagnosis codes is a marker of comorbidity and was originally formulated to predict mortality. ${ }^{11}$ The Carstairs index of deprivation is derived from the patient's postcode. ${ }^{12}$ Deaths within 365 days are derived through linkage between HES records and the Office of National Statistics and are available in this dataset for patients admitted to hospital between 1 April 2000 and 31 March 2005 because of a delay in linkage. ${ }^{13}$

\section{Database inclusions and variable coding}

All adult patients undergoing primary colorectal resections were included from 1 April 2000 to 31 March 2008. Any of these patients who had undergone a previous colorectal resection between 1996 and 2000 was excluded from the analysis. The first resection that the patient underwent between 2000 and 2008 was considered as the primary resection.

They were categorised according to the site of resection (OPCS-4 coding) as shown in table 1. A laparoscopic procedure was considered to be any procedure associated with OPCS-4 codes Y50.8, Y75, or Y71.4 (Y71.4 (failed minimal access) was introduced in 2006). Procedures coded to failed minimal access were considered in the laparoscopic group for analysis.

Individual diagnoses were recoded into major diagnostic categories according to ICD-10 code as follows: C18, C19, C20, $\mathrm{C} 21$, and $\mathrm{C} 26$ for malignant disease; K51 for ulcerative colitis; K50 for Crohn's disease; and K57 for diverticular disease. The remaining codes were classified as "other." Patients were grouped into four age cohorts: $17-54,55-69,70-79$, and $>79$ years according to age at time of surgery. The Charlson comorbidity score was considered in three categories: $0,1-4$, and $\geq 5$. A hospital trust may comprise several sites. Because of mergers, hospital trust codes were unified to reflect their status as of April 2008.

\section{Outcome variables}

Reoperation was defined as any reoperation for an intra-abdominal procedure or wound complication on the index admission or on a subsequent admission to hospital within 28 days of the initial resection. Reoperation rates were classified according to type of operation. These were divided into laparotomy (considered as a reopening of abdomen, washout of abdomen, small bowel resection, further colorectal resection, open procedure for intra-abdominal abscess, division of adhesions, and formation of stoma), stoma complications (considered as an operation on a stoma, excluding closure of stoma and stoma formation), wound complications requiring reoperation, and "other" (for other reasons for reoperation).

We ascertained 30 day mortality in hospital and 365 day total postoperative mortality (for all causes in both cases). Patients from the study years after March 2005 were excluded from the analysis of 365 day mortality.

Length of stay is the time (in days) spent in hospital during the primary admission for colorectal resection. Median length of stay (with interquartile range) is referred to in unadjusted analyses.

Readmission refers to emergency (unplanned) readmission to hospital within 28 days of the index admission for any reason.

To reduce the potential impact of coding errors and capture the true caseload of the hospital trusts and consultant teams for the construction of the funnel plots, we included only those trusts that performed $>10$ resections over the period and consultant teams that performed $\geq 5$ resections over the period. Anonymised identifiers were used to calculate readmission rates for individual consultant teams and hospital trusts. Patients were coded according to the consultant team and trust assigned to the episode with the index procedure.

\section{Statistical methodology}

Categorical variables were investigated with the $\chi^{2}$ test. Logistic regression analysis was used to investigate postoperative reoperation rate. Factors with a significance level of $\leq 0.1$ on bivariate analysis were included in the regression analyses.

Statistical analyses were carried out with SPSS version 18.0 (SPSS, Chicago, Illinois, USA). For tests of significance, $\mathrm{P}$ values $<0.05$ was considered significant. For non-normal variables, the median and interquartile range are given. We constructed funnel plots using exact Poisson control limits by means of the web tool available at www.erpho.org.uk/topics/ tools/funnel.aspx.

\section{Results \\ Demographics}

Between 1 April 2000 and 31 March 2008, 246469 patients who underwent a primary colorectal resection in 175 English hospital trusts were included. Of these, 158847 (64.4\%) patients underwent resection during an elective admission, 87472 $(35.5 \%)$ were emergency admissions, and 150 had no record of their admission status. Table 2 summarises the characteristics of elective and emergency patients undergoing resection included in this study and the relative numbers of elective patients undergoing open and laparoscopic procedures.

\section{Reoperation}

The overall postoperative reoperation rate for all patients undergoing colorectal resection irrespective of admission status was $6.5 \%$ (15 986/246 469). Of these, $13227(82.7 \%)$ required a reoperation on their primary admission. The remaining 2759 patients underwent a subsequent admission that included a reoperation. Emergency patients experienced slightly higher rates of reoperation than elective patients $(7.0 \%(6156 / 87472)$ $v 6.2 \%(9819 / 158$ 847), $\mathrm{P}<0.001)$. A total of $11536(4.7 \%)$ 
underwent re-laparotomy after colorectal resection, $1560(0.6 \%)$ experienced a subsequent stoma related complication requiring surgery, and 3861 (1.6\%) had a wound complication requiring reoperation. Overall, for both elective and emergency patients, those who had a resection attempted by a minimal access approach had a marginally higher rate of reoperation than those who had undergone an open approach (laparoscopic 7.0\% (799/11 359) $v$ open 6.5\% (15 187/235 110), $\mathrm{P}=0.015)$. Table 3 shows the reasons for reoperation, and table 4 lists the characteristics of the patients who required reoperation.

\section{Patient characteristics and reoperation}

Table 5 describes the predictors of reoperation in patients who underwent colorectal resection, including multiple regression analyses for patients undergoing reoperation for laparotomy specifically. On multiple regression analysis, younger age, a diagnosis of inflammatory bowel disease, increasing comorbidity, male sex, rectal and total resection, a laparoscopic approach, and emergency admission were independent predictors of both reoperation and laparotomy after surgery (table 5). Increasing social deprivation predicted a higher reoperation rate but was not significant for laparotomy.

\section{Correlation with other outcome measures}

Elective and emergency patients who experienced a complication requiring reoperation during their initial admission had a prolonged median length of stay (for elective patients, length of stay 27 (interquartile range 17-43) days with reoperation $(\mathrm{n}=7873) v 11(9-16)$ days with no reoperation $(\mathrm{n}=150974), \mathrm{P}<0.001$; for emergency patients, length of stay 34 (21-55) days with reoperation $(\mathrm{n}=5401) v 17(11-28)$ days with no reoperation $(\mathrm{n}=82071), \mathrm{P}<0.001)$. They also had a higher rate of postoperative mortality (elective patients, 938/7873 (11.9\%) with reoperation $v 4399 / 150974$ (2.9\%) with no reoperation, $\mathrm{P}<0.001$; emergency patients, $1251 / 5346$ $(23.4 \%)$ with reoperation $v 12511 / 82126$ (15.2\%) with no reoperation, $\mathrm{P}<0.001)$.

The increased mortality after reoperation persisted in multiple regression analysis (table 6). One year mortality was available from April 2000 to March 2004. Patients who experienced a complication requiring reoperation either on the index admission or a subsequent admission within 28 days of surgery had an increased one year mortality (for elective patients, mortality 1353/57 546 (23.9\%) with reoperation $v 10$ 162/89 800 (11.3\%) with no reoperation, $\mathrm{P}<0.001$; for emergency patients, mortality $1477 / 3693$ (40.0\%) with reoperation $v 15$ 030/50 822 (29.6\%) with no reoperation, $\mathrm{P}<0.001)$. Elective patients who required a reoperation on the index admission had a higher emergency readmission rate within 28 days of discharge after this index admission (947/7873 (12.0\%) with reoperation $v 13$ 777/150 $974(9.1 \%)$ with no reoperation, $\mathrm{P}<0.001)$.

\section{Variation in reoperation between surgeons and hospital trusts}

Exclusion of trust and surgeon codes that failed to meet the minimum volume inclusion criteria equated to 19 trusts (37 patients $(0.02 \%)$ ) and 4185 consultant codes (6853 patients $(2.8 \%))$. Of the patients excluded in the analysis of surgeon codes, $72.2 \%$ were assigned to an emergency admission.

For included consultant teams, reoperation rates after elective procedures varied between none and 50\%. Variation between trusts for all procedures was between none and $17 \%$. Figures 1 and 2 show funnel plots of the adjusted reoperation rates among consultant teams and NHS trusts. Wide variation in reoperation rates can be observed across all caseloads.

Of the 156 included trusts, 22 had adjusted reoperation rates outside (that is, above) the $99.8 \%$ control limit, which corresponds to 3 standard deviations above the mean. For 156 trusts, 0.16 trust outliers at this threshold could be expected to arise through chance alone, assuming a purely binomial distribution for the reoperations. Eleven $(0.7 \%)$ of the 1557 included consultant teams had elective reoperation rates above the $99.8 \%$ control limit, while 1.6 consultant team outliers at this threshold would be expected through chance alone.

Even at a high caseload, however, there was substantial variation in both the trust and surgeon team reoperation rates. There was a fivefold difference in highest and lowest reoperation rates after elective surgery (14.9\% v 2.8\%) among the surgical teams performing $>500$ procedures. There was a threefold difference in reoperation rates in trusts performing $>2500$ procedures during the study period $(11.5 \% v 3.7 \%)$.

\section{Discussion}

We report national reoperation rates after major colorectal resection in England. Reoperation represents a possible performance indicator that could be derived from existing data sources. Moreover, we have shown the feasibility of using routinely collected data to measure institutional and surgeon reoperation rates on a national scale and demonstrated substantial variation in reoperation rates between providers of colorectal services. The methodology underpinning this indicator is widely applicable to other surgical specialties. If coding accuracy can be assured, we suggest that reoperation rates, along with existing quality indicators such as mortality, could offer a powerful means of checking quality of surgical care.

\section{Comparison with other studies}

The reoperation rates described in this study are consistent with those found by studies from the American Surveillance, Epidemiology and End Results (SEER) and the National Surgical Quality Improvement Programme data. ${ }^{74}{ }^{15}$ We feel that our method of deriving reoperation rates from the UK administrative dataset used in this study is a valid way of investigating postoperative outcome. Data from individual hospitals are submitted centrally from local institution administrative computer systems. Thus, these systems could potentially be used for real time monitoring of postoperative outcome in a reproducible way through existing institution databases. Since clinical coders enter the data rather than the clinical teams caring for patients, the data have a degree of objectivity. Moreover, the data represent an opportunity to report the outcome of all resections performed by all surgeons in the entire country.

Outliers existed throughout the spectrum of institutional and surgical team caseload, suggesting that increasing caseload may not necessarily lead to an improvement in outcome. Increasing caseload among those providers who have good outcomes rather than increasing volume indiscriminately may lead to greater quality improvements. The uses of an indicator such as reoperation are not limited to colorectal surgery. The longitudinal methodology used in this study is easily applicable across a range of surgical specialties that are associated with high morbidity such as upper gastrointestinal or vascular surgery.

For a quality indicator to be valid, it must be reliable. We consider the methodology used in this study to be reliable. 
Although clinical registry and administrative datasets are incomplete and contain a degree of error, administrative data in England include all patients admitted to hospital. In addition, a systematic review suggested that the accuracy of procedure coding of UK administrative data was $97 \% .{ }^{16}$ Moreover, Hospital Episode Statistics data have compared favourably with clinical registry data, ${ }^{17-20}$ and it is widely accepted that the accuracy of data recording is improving.

For a quality marker to be useable, it needs to reflect adequately the likely variation due to patient factors. In the current study, elective patients selected for a laparoscopic approach experienced relatively high reoperation rates, with $7.1 \%$ of elective laparoscopic patients requiring reoperation after the primary resection. A study of National Surgical Quality Improvement Programme data by Bilimoria and colleagues found equivalent reoperation rates in patients having laparoscopic or open surgery $(5.5 \% v 5.8 \%, \mathrm{P}=0.79),{ }^{15}$ but this study was limited to elective cancer patients undergoing colectomy. A further study using National Surgical Quality Improvement Programme data, examining outcome following colectomy for all diagnoses, found a similar small increase in the adjusted reoperation rate following laparoscopic resection when compared with the open approach $(\mathrm{OR}=1.78, \mathrm{p}=0.002) .{ }^{21}$ Further studies are required to see if this increase in reoperation rate is a result of laparoscopy itself or temporal factors. Laparoscopy has been shown to correlate with improved mortality, morbidity, and length of stay following colectomy. ${ }^{10}$ These data concerning the possible risk of reoperation will allow surgeons and patients to make more informed decisions about management options.

Increasing socioeconomic deprivation is associated with higher reoperation rates and has been shown to be a factor in determining the type of surgery that patients undergo. Patients from areas of increased social deprivation are more likely to undergo an abdominoperineal resection than others. ${ }^{322}$ Poorer survival after treatment of colorectal cancer, especially after surgical resection, has been found..$^{1023}$ The disparity in outcome seen in this study may reflect severity of disease at presentation or other unquantified characteristics. The increase in reoperation rates with increasing socioeconomic deprivation suggests that work is required to redress this inequality through quality improvement and early detection of disease.

Although older patients have been shown to have poorer postoperative mortality ${ }^{24}$ and increased morbidity such as postoperative medical complications, older patients have not been found to have higher reoperation rates. ${ }^{25}$ This may reflect a reluctance of surgeons to take older patients back to theatre after surgery. Older patients may not be fit for a further procedure or may die before returning to theatre after a complication. Further research is required to target decision making among surgeons treating older patients.

Other indicators of quality have been suggested in colorectal surgery, including structural indicators such as operative caseload and process indicators such as abdominoperineal excision rate for rectal cancer, quality of mesorectal excision and circumferential resection margin positivity rate, lymph node yield, and preoperative use of neoadjuvant therapy. ${ }^{26}$ In addition to mortality, proposed outcome indicators include readmission rates, duration of hospital stay, and long term markers of oncological success (local recurrence and survival). It is necessary to ensure that quality indicators reflect the proficiency of appropriate professional groups within a multidisciplinary team. To improve performance among surgeons, measurement of factors that are within surgeons' remit (such as reoperation rate, intraoperative blood loss, and abdominoperineal excision rate) is relevant. It is important to recognise, however, that some indicators (such as lymph node harvest, adjuvant chemotherapy rate) also reflect the performance of affiliated professionals. Quality improvement in these domains therefore demands a multiprofessional approach.

Reoperation potentially reflects an important aspect of quality of perioperative surgical care. Reoperation often occurs for reasons of surgical morbidity, such as postoperative bleeding and anastomotic leaks. The need for reoperation significantly increases postoperative mortality in the short term (table 5). Reoperation is also associated with poor long term outcome, including higher risk of local recurrence and poorer overall survival where resection has been undertaken for cancer. There are, however, many possible reasons why a surgeon or hospital trust may erroneously achieve outlier status, including data quality or operative case mix. Genuine outlier status must therefore be confirmed by excluding easily explainable sources of variance.

\section{Strengths and limitations of the study}

The advantage of this administrative dataset is that it provides a comprehensive overview of current colorectal practice in England. By including all patients admitted to NHS hospitals in England, any submission bias is avoided. The dataset, although prospectively collected, includes all patients undergoing surgery without standardisation of treatment, and selection bias of procedure or management by individual surgeons or trusts cannot be excluded. The dataset lacks clinical information such as disease severity that would allow a more refined risk adjustment for comparison of institutions or surgeons. Information such as cancer stage, which has been suggested to affect the risk of poor outcome such as anastomotic leakage, is not available on this dataset. ${ }^{27}$ It is, however, feasible to link the Hospital Episode Statistics database with cancer registry data. ${ }^{5}$ This approach would enable application of our proposed methodology to a linked dataset that offered improved adjustment for case mix in cancer cases.

The primary explanatory variables that predicted for surgical outcome included comorbidity, diagnosis, and age. We did not include training centre as a confounder. It could be argued that service quality should be maintained by an institution irrespective of training status in a public system such as the NHS.

Derivation of the reoperation rates in this study relied on the secondary procedure codes. The accuracy of secondary codes may be less than that of the primary codes. The Charlson score, which is also based on secondary diagnosis coding, was used to adjust for comorbidity in the population. Although originally derived to predict mortality, the Charlson index has been shown to be valid for comorbidity adjustment in patients with colorectal cancer. ${ }^{28}$ The Charlson score has also been used to adjust for comorbidity in predicting surgical complications in the United States. $^{29}$

Datasets that contain physiological data, such as the National Surgical Quality Improvement Programme data, may provide superior risk adjustment. A bespoke dataset in the United Kingdom would, however, be required to link Hospital Episode Statistics data with this information along with other factors such as disease severity. Linkage of routinely collected data to other datasets, such as the cancer registry, has been done previously. ${ }^{35}$ Future linkage with other data sources will permit improved adjustment for case mix. It is not possible to ascertain, however, whether this refinement in risk adjustment would alter 
the adjusted reoperation rates to the extent that different outliers would be identified.

Trusts may vary in the accuracy to which they record secondary procedures or diagnosis codes. Some of the variability between trusts seen in this study may reflect differences in local coding practices.

The OPCS- 4 code for conversion of a minimal access to an open procedure was introduced in 2006. Any such cases before the introduction of this code will not have been captured as conversions, and they may have been included in the open surgery group of patients before 2006. For the purposes of this analysis, cases converted to open procedure and those coded to the laparoscopic code were considered together as the laparoscopic group.

For this analysis, given the inclusion of emergency patients, patients coded to a Hartmann's procedure (H33.5) were included in the group who underwent left sided resection. Most of these cases had a diagnosis of diverticular disease, and we therefore thought these resections were more likely to be sigmoid resections rather than true rectal resections.

Surgical complications that do not require reoperation, such as wound infection treated by antibiotics, are not included in this study. Interventional radiological procedures such as image guided drain insertion are also not included. Thus the total surgical morbidity that may have an impact on outcome, including length of stay and mortality, will be underestimated in this study.

Surgeons may differ in their threshold for taking patients back to theatre, reflecting differences in surgeon level reoperation rates. Furthermore, in this study all reoperations were included as it was not possible to differentiate between those that were planned and those that were unplanned. A small minority of the reoperations will represent a planned "second look" procedure.

\section{Conclusion and policy implications}

This study supports the feasibility of using reoperation rate as a quality indicator derived from routinely collected data. If data accuracy can be assured, this methodology may permit national performance assessment using reoperation alongside other indicators such as mortality and will be easily transferable across a range of surgical specialties. Initiatives to improve surgical performance should be focused on reducing inexplicable observed variation in reoperation after major resectional colorectal surgery.

A portion of this work based on the same dataset has been presented at the European Society of Coloproctology meeting, Sorrento, September 2010; the Association of Coloproctology of Great Britain and Ireland meeting, Birmingham, June 2011; and the Tripartite Colorectal meeting, Cairns, July 2011.

Contributors: EMB performed all analyses, developed the concept, and produced the manuscript. AB developed the concept, provided statistical advice, and edited the manuscript. PA developed the concept, provided statistical advice, and edited the manuscript. AD developed the concept and edited the manuscript. RJN developed the concept and edited the manuscript. OF developed the concept, advised on analyses, provided statistical advice, and edited the manuscript. OF and EB act as guarantors of the data.

Funding: The Dr Foster Unit at Imperial is largely funded by a research grant from Dr Foster Intelligence (an independent health service research organisation). The unit is affiliated with the Centre for Patient Safety and Service Quality at Imperial College Healthcare NHS Trust, which is funded by the National Institute of Health Research (NIHR). We are grateful for support from the NIHR Biomedical Research Centre funding scheme. This research is independent of any bodies funding the authors of this research.

Competing interests: All authors have completed the Unified Competing Interest form at www.icmje.org/coi_disclosure.pdf (available on request from the corresponding author) and declare: no support from any organisation for the submitted work; no financial relationships with any organisations that might have an interest in the submitted work in the previous three years, no other relationships or activities that could appear to have influenced the submitted work.

Ethical approval: This work was approved under Section 251 (formerly Section 60) granted by the National Information Governance Board for Health and Social Care (formerly the Patient Information Advisory Group), and approved by the South East Research Ethics Committee. Data sharing: No additional data available.

1 Alves A, Panis Y, Mathieu P, Mantion G, Kwiatkowski F, Slim K. Postoperative mortality and morbidity in French patients undergoing colorectal surgery: results of a prospective multicenter study. Arch Surg 2005;140:278-83, discussion 84.

2 Faiz O, Brown T, Bottle A, Burns EM, Darzi AW, Aylin P. Impact of hospital institutional volume on postoperative mortality after major emergency colorectal surgery in English National Health Service Trusts, 2001 to 2005. Dis Colon Rectum 2010;53:393-401.

3 Morris E, Quirke P, Thomas JD, Fairley L, Cottier B, Forman D. Unacceptable variation in abdominoperineal excision rates for rectal cancer: time to intervene? Gut 2008;57:1690-7.

4 McArdle CS, Hole D. Impact of variability among surgeons on postoperative morbidity and mortality and ultimate survival. BMJ 1991;302:1501-5.

5 Morris EJ, Taylor EF, Thomas JD, Quirke P, Finan PJ, Coleman MP, et al. Thirty-day postoperative mortality after colorectal cancer surgery in England. Gut 2011;60:806-13.

6 Birkmeyer JD, Hamby LS, Birkmeyer CM, Decker MV, Karon NM, Dow RW. Is unplanned return to the operating room a useful quality indicator in general surgery? Arch Surg 2001:136:405-11.

7 Morris AM, Baldwin LM, Matthews B, Dominitz JA, Barlow WE, Dobie SA, et al. Reoperation as a quality indicator in colorectal surgery: a population-based analysis. Ann Surg 2007;245:73-9.

8 Merkow RP, Bilimoria KY, Cohen ME, Richards K, Ko CY, Hall BL. Variability in reoperation rates at 182 hospitals: a potential target for quality improvement. J Am Coll Surg 2009;209:557-64.

9 Mirnezami A, Mirnezami R, Chandrakumaran K, Sasapu K, Sagar P, Finan P. Increased local recurrence and reduced survival from colorectal cancer following anastomotic leak: systematic review and meta-analysis. Ann Surg 2011;253:890-9.

10 Faiz O, Warusavitarne J, Bottle A, Tekkis PP, Darzi AW, Kennedy RH. Laparoscopically assisted vs open elective colonic and rectal resection: a comparison of outcomes in English National Health Service Trusts between 1996 and 2006. Dis Colon Rectum 2009:52:1695-704

11 Charlson ME, Pompei P, Ales KL, MacKenzie CR. A new method of classifying prognostic comorbidity in longitudinal studies: development and validation. $J$ Chronic Dis 1987:40:373-83.

12 Carstairs V, Morris R. Deprivation: explaining differences in mortality between Scotland and England and Wales. BMJ 1989;299:886-9.

13 HES/ONS. Linkage methodology. 2002. http://nchod.uhce.ox.ac.uk/NCHOD\%200xford\% 20E5\%20Report\%201st\%20Feb_VerAM2.pdf.

14 Billingsley KG, Morris AM, Green P, Dominitz JA, Matthews B, Dobie SA, et al. Does surgeon case volume influence nonfatal adverse outcomes after rectal cancer resection? J Am Coll Surg 2008:206:1167-77.

15 Bilimoria KY, Bentrem DJ, Merkow RP, Nelson H, Wang E, Ko CY, et al.

Laparoscopic-assisted vs open colectomy for cancer: comparison of short-term outcomes from 121 hospitals. J Gastrointest Surg 2008;12:2001-9.

16 Campbell SE, Campbell MK, Grimshaw JM, Walker AE. A systematic review of discharge coding accuracy. J Public Health Med 2001;23:205-11.

17 Aylin P, Bottle A, Elliott P, Jarman B. Surgical mortality: hospital episode statistics v central cardiac audit database. BMJ 2007:335:839, author reply 39-40.

18 Aylin P, Bottle A, Majeed A. Use of administrative data or clinical databases as predictors of risk of death in hospital: comparison of models. BMJ 2007;334:1044.

19 Aylin P, Lees T, Baker S, Prytherch D, Ashley S. Descriptive study comparing routine hospital administrative data with the Vascular Society of Great Britain and Ireland's national vascular database. Eur J Vasc Endovasc Surg 2007;33:461-5, discussion 66.

20 Garout M, Tilney HS, Tekkis PP, Aylin P. Comparison of administrative data with the Association of Coloproctology of Great Britain and Ireland (ACPGBI) colorectal cancer database. Int J Colorectal Dis 2008;23:155-63.

21 Delaney CP, Chang E, Senagore AJ, Broder M. Clinical outcomes and resource utilization associated with laparoscopic and open colectomy using a large national database. Ann Surg 2008;247:819-24.

22 Tilney H, Lovegrove RE, Smith JJ, Thompson MR, Tekkis PP. The National Bowel Cance Project: social deprivation is an independent predictor of nonrestorative rectal cancer surgery. Dis Colon Rectum 2009;52:1046-53.

23 Wrigley H, Roderick P, George S, Smith J, Mullee M, Goddard J. Inequalities in survival from colorectal cancer: a comparison of the impact of deprivation, treatment, and host factors on observed and cause specific survival. J Epidemiol Community Health 2003;57:301-9.

24 Faiz O, Haji A, Bottle A, Clark S, Darzi A, Aylin P. Elective colonic surgery for cancer in the elderly: an investigation into postoperative mortality in English NHS hospitals between 1996 and 2007. Colorectal Dis 2011;13:779-85.

25 Bentrem DJ, Cohen ME, Hynes DM, Ko CY, Bilimoria KY. Identification of specific quality improvement opportunities for the elderly undergoing gastrointestinal surgery. Arch Surg 2009;144:1013-20. 


\section{What is already known on this topic}

Reoperation rate has been suggested as a quality indicator of surgery in the United States

To check performance and quality in colorectal surgery, other quality indicators are needed in addition to mortality and need to be evidence based

\section{What this study adds}

This study of Hospital Episode Statistics data for reoperation after colorectal resection showed considerable variation in reoperation rates in English NHS hospitals

Inflammatory bowel disease, multiple other comorbidity, increasing social deprivation, male sex, rectal resection, use of laparoscopic surgery, and emergency admission were independently associated with higher risk of reoperation

Reoperation after colorectal surgery is a possible quality indicator to be used alongside existing indicators such as mortality

Almoudaris A, Clark S, Vincent C, Faiz O. Establishing quality in colorectal surgery. Colorectal Dis 2010: pubished online 19 April.

27 Boccola MA, Buettner PG, Rozen WM, Siu SK, Stevenson AR, Stitz R, et al. Risk factors and outcomes for anastomotic leakage in colorectal surgery: a single-institution analysis of 1576 patients. World J Surg 2011;35:186-95.

28 Ouellette JR, Small DG, Termuhlen PM. Evaluation of Charlson-Age Comorbidity Index as predictor of morbidity and mortality in patients with colorectal carcinoma. $J$ Gastrointest Surg 2004;8:1061-7.
29 Kemp JA, Finlayson SR. Outcomes of laparoscopic and open colectomy: a national population-based comparison. Surg Innov 2008;15:277-83.

Accepted: 15 June 2011

Cite this as: $B M J 2011 ; 343: \mathrm{d} 4836$ 


\section{Tables}

Table 1| OPCS-4 codes used to define colorectal resection

\begin{tabular}{ll}
$\begin{array}{ll}\text { Resection type } \\
\text { Right sided resection }\end{array}$ & \multicolumn{1}{c}{ OPCS-4 codes } \\
\cline { 2 - 2 } Reft sided resection hemicolectomy (H07) & Extended right hemicolectomy and transverse colectomy (H06, H08) \\
\cline { 2 - 2 } & \begin{tabular}{ll} 
Left hemicolectomy (H09) \\
\cline { 2 - 2 } Sigmoid colectomy (H10)
\end{tabular} \\
\hline Total colectomy & Panproctocolectomy (H04.1, H04.3, H04.8, H04.9) \\
\cline { 2 - 2 } & Total colectomy (H05) \\
\cline { 2 - 2 } Colectomy of unspecified site (H11) \\
\hline Rectal resection & Anterior resection (H33.2, H33.3, H33.4, H33.6, H33.7, H33.8, H33.9) \\
\cline { 2 - 2 } & Abdominoperineal resection (APE H33.1) \\
\hline
\end{tabular}


Table 2| Characteristics and details of surgery of 246469 patients undergoing a colorectal resection in English NHS trusts between 1 April 2000 and 31 March 2008. Values are numbers (percentages) of patients unless stated otherwise

\section{Elective surgery}

Laparoscopic ( $n=10$ 131) Open approach $(n=148$ 716) P value of difference Emergency surgery $(n=87472)$

Resection type:

\begin{tabular}{|c|c|c|c|c|}
\hline Right sided & 3627 (35.8) & $42229(28.4)$ & \multirow[t]{4}{*}{$<0.001$} & $34962(40.0)$ \\
\hline Left sided & $2237(22.1)$ & $36085(24.3)$ & & 34825 (39.8) \\
\hline Rectal & $3836(37.9)$ & $59479(40.0)$ & & $5604(6.4)$ \\
\hline Total colectomy & $431(4.3)$ & $10923(7.3)$ & & $12081(13.8)$ \\
\hline \multicolumn{5}{|l|}{ Diagnosis: } \\
\hline Colorectal cancer & $6673(65.9)$ & $104352(70.2)$ & \multirow[t]{4}{*}{$<0.001$} & $33493(38.3)$ \\
\hline Inflammatory bowel disease & $758(7.5)$ & $10684(7.2)$ & & $9201(10.5)$ \\
\hline Diverticular disease & $1051(10.4)$ & $13063(8.8)$ & & $18915(21.6)$ \\
\hline Other & $1649(16.3)$ & $20617(13.9)$ & & $25863(29.6)$ \\
\hline \multicolumn{5}{|l|}{ Age (years): } \\
\hline $17-54$ & $1957(19.3)$ & $25568(17.2)$ & \multirow[t]{4}{*}{$<0.001$} & $20021(22.9)$ \\
\hline $55-69$ & 3409 (33.6) & $51536(34.7)$ & & $23909(27.3)$ \\
\hline $70-79$ & $3096(30.6)$ & $48221(32.4)$ & & $24582(28.1)$ \\
\hline$>79$ & $1669(16.5)$ & $23391(15.7)$ & & $18960(21.7)$ \\
\hline \multicolumn{5}{|l|}{ Charlson score: } \\
\hline 0 & $6908(68.2)$ & $96658(65.0)$ & \multirow[t]{3}{*}{$<0.001$} & $54581(62.4)$ \\
\hline $1-4$ & $1172(11.6)$ & $13665(9.2)$ & & $8312(9.5)$ \\
\hline$\geq 5$ & $2051(20.2)$ & $38393(25.8)$ & & $24579(28.1)$ \\
\hline Carstairs deprivation index*: & $\mathrm{n}=10126$ & $n=148585$ & & $\mathrm{n}=87417$ \\
\hline 1 (least deprived) & $2285(22.6)$ & $29107(19.6)$ & \multirow[t]{5}{*}{$<0.001$} & $15225(17.4)$ \\
\hline 2 & $2456(24.2)$ & $34589(23.3)$ & & $18221(20.8)$ \\
\hline 3 & $2216(21.9)$ & $32694(22.0)$ & & $18932(21.6)$ \\
\hline 4 & 1770 (17.5) & $28910(19.4)$ & & $18427(21.1)$ \\
\hline 5 (most deprived) & $1398(13.8)$ & $23285(15.7)$ & & $16612(19.0)$ \\
\hline \multicolumn{5}{|l|}{ Sex: } \\
\hline Men & $4920(48.6)$ & 79234 (53.3) & \multirow[t]{2}{*}{$<0.001$} & 40819 (46.7) \\
\hline Women & $5211(51.4)$ & $69482(46.7)$ & & $46653(53.3)$ \\
\hline
\end{tabular}

*Social deprivation status not recorded for 55 emergency patients and 137 elective patients (6 laparoscopic and 131 open approach). 
Table 3| Reasons for reoperation after colorectal resection among 246469 patients in English NHS trusts between 1 April 2000 and 31 March 2008. Values are numbers (percentages) of patients unless stated otherwise

\begin{tabular}{|c|c|c|c|c|c|}
\hline & \multicolumn{4}{|c|}{ Elective surgery } & \multirow[b]{2}{*}{$\begin{array}{l}\text { Emergency surgery } \\
\qquad(n=87472)\end{array}$} \\
\hline & Total $(n=158847)$ & $\begin{array}{l}\text { Laparoscopic } \\
(n=10131)\end{array}$ & $\begin{array}{l}\text { Open approach } \\
(n=148716)\end{array}$ & $P$ value of difference ${ }^{*}$ & \\
\hline Any reoperation & $9819(6.2)$ & $718(7.1)$ & $9413(6.1)$ & $<0.001$ & $6156(7.0)$ \\
\hline Laparotomy: & $7142(4.5)$ & $541(5.3)$ & $6601(4.4)$ & $<0.001$ & $4387(5.0)$ \\
\hline Reopening of abdomen & $2617(1.6)$ & $129(1.3)$ & $2488(1.7)$ & 0.002 & $1733(2.0)$ \\
\hline Open procedure for abscess & $463(0.3)$ & $31(0.3)$ & $432(0.3)$ & 0.779 & $264(0.3)$ \\
\hline Washout & $1485(0.9)$ & $127(1.3)$ & $1358(0.9)$ & 0.001 & $1015(1.2)$ \\
\hline Small bowel operation & $966(0.6)$ & $105(1.0)$ & $861(0.6)$ & $<0.001$ & $644(0.7)$ \\
\hline Colorectal resection & $1661(1.0)$ & $166(1.6)$ & $1495(1.0)$ & $<0.001$ & $944(1.1)$ \\
\hline Division of early adhesions & $760(0.5)$ & $47(0.5)$ & $713(0.5)$ & 0.827 & $381(0.4)$ \\
\hline Formation of stoma & $2596(1.6)$ & $241(2.4)$ & $2355(1.6)$ & $<0.001$ & $1202(1.4)$ \\
\hline Stoma complication & $704(0.4)$ & $50(0.5)$ & $654(0.4)$ & 0.430 & $856(1.0)$ \\
\hline Wound complication & $2243(1.4)$ & $145(1.4)$ & $2098(1.4)$ & 0.866 & $1616(1.8)$ \\
\hline \multicolumn{6}{|l|}{ Other: } \\
\hline Spleen or liver injury & $90(0.1)$ & $4(0.0)$ & $86(0.1)$ & 0.453 & $80(0.1)$ \\
\hline Urological procedures & $192(0.1)$ & $11(0.1)$ & $181(0.1)$ & 0.713 & $97(0.1)$ \\
\hline Repair of incisional hernia & $84(0.0)$ & $36(0.4)$ & $48(0.0)$ & $<0.001$ & $30(0.0)$ \\
\hline $\begin{array}{l}\text { Examination under anaesthesia or } \\
\text { operation on rectum }\end{array}$ & $415(0.3)$ & $32(0.3)$ & $383(0.3)$ & 0.266 & $101(0.1)$ \\
\hline Perineal operation & $396(0.2)$ & $18(0.2)$ & $402(0.3)$ & 0.077 & $56(0.1)$ \\
\hline
\end{tabular}


Table 4| Characteristics of patients requiring a reoperation in the postoperative period after colorectal resection among 246469 patients in English NHS trusts between 1 April 2000 and 31 March 2008. Values are numbers (percentages) of patients unless stated otherwise

\section{Elective surgery}

Reoperation No reoperation $\mathbf{P}$ value of difference

Emergency surgery

Reoperation No reoperation $\mathbf{P}$ value of difference

Resection type:

\begin{tabular}{|c|c|c|c|c|c|c|}
\hline Right sided & $1974(4.3)$ & $43882(95.7)$ & \multirow[t]{4}{*}{$<0.001$} & $2181(6.2)$ & 32781 (93.8) & \multirow[t]{4}{*}{$<0.001$} \\
\hline Left sided & $2284(6.0)$ & $36038(94.0)$ & & $2546(7.3)$ & $32279(92.7)$ & \\
\hline Rectal & $4659(7.4)$ & $58656(92.6)$ & & $428(7.6)$ & $5176(92.4)$ & \\
\hline Total colectomy & $902(7.9)$ & $10452(92.1)$ & & $1001(8.3)$ & $11080(91.7)$ & \\
\hline \multicolumn{7}{|l|}{ Diagnosis: } \\
\hline Colorectal cancer & $6566(5.9)$ & $104459(94.1)$ & \multirow[t]{4}{*}{$<0.001$} & $1983(5.9)$ & $31510(94.1)$ & \multirow[t]{4}{*}{$<0.001$} \\
\hline Inflammatory bowel disease & $782(6.8)$ & $10660(93.2)$ & & $739(8.0)$ & $8462(92.0)$ & \\
\hline Diverticular disease & $845(6.0)$ & $13269(94.0)$ & & $1335(7.1)$ & $17580(92.9)$ & \\
\hline Other & $1626(7.3)$ & $20640(92.7)$ & & $2099(8.1)$ & 23764 (91.9) & \\
\hline \multicolumn{7}{|l|}{ Age (years): } \\
\hline $17-54$ & $1847(6.7)$ & $25678(93.3)$ & \multirow[t]{4}{*}{$<0.001$} & $1570(7.8)$ & $18451(92.2)$ & \multirow[t]{4}{*}{$<0.001$} \\
\hline $55-69$ & $3576(6.5)$ & $51369(93.5)$ & & $1868(7.8)$ & $22041(92.2)$ & \\
\hline $70-79$ & $3218(6.3)$ & $48099(93.7)$ & & $1805(7.3)$ & $22777(92.6)$ & \\
\hline$>79$ & $1178(4.7)$ & $23882(95.3)$ & & $913(4.8)$ & $18047(95.2)$ & \\
\hline \multicolumn{7}{|l|}{ Charlson score: } \\
\hline 0 & $5880(5.7)$ & $97686(94.3)$ & \multirow[t]{3}{*}{$<0.001$} & $3725(6.8)$ & $50856(93.2)$ & \multirow[t]{3}{*}{0.001} \\
\hline $1-4$ & $974(6.6)$ & $13863(93.4)$ & & $576(6.9)$ & $7736(93.1)$ & \\
\hline$\geq 5$ & $2965(7.3)$ & $37479(92.7)$ & & $1855(7.5)$ & 22724 (92.5) & \\
\hline \multicolumn{7}{|l|}{ Carstairs deprivation index: } \\
\hline 1 (least deprived) & $1849(5.9)$ & $29543(94.1)$ & \multirow[t]{5}{*}{$<0.001$} & $1037(6.8)$ & $14188(93.2)$ & \multirow[t]{5}{*}{0.044} \\
\hline 2 & $2175(5.9)$ & $34870(94.1)$ & & $1221(6.7)$ & $17000(93.3)$ & \\
\hline 3 & $2161(6.2)$ & $32749(93.7)$ & & $1319(7.0)$ & $17613(93.0)$ & \\
\hline 4 & $1929(6.3)$ & $28751(93.1)$ & & $1353(7.3)$ & $17074(92.7)$ & \\
\hline 5 (most deprived) & $1697(6.9)$ & $22986(93.1)$ & & $1223(7.4)$ & $15389(92.6)$ & \\
\hline \multicolumn{7}{|l|}{ Sex: } \\
\hline Men & $6080(7.2)$ & 78074 (92.8) & \multirow[t]{2}{*}{$<0.001$} & $3164(7.8)$ & 37655 (92.2) & \multirow[t]{2}{*}{$<0.001$} \\
\hline Women & $3739(5.0)$ & $70954(95.0)$ & & $2992(6.6)$ & $43661(93.6)$ & \\
\hline
\end{tabular}


Table 5| Multiple regression analysis for reoperation and laparotomy after colorectal resection among 246469 patients in English NHS trusts between 1 April 2000 and 31 March 2008

\begin{tabular}{|c|c|c|}
\hline \multicolumn{3}{|c|}{ All reoperation } \\
\hline \multirow[b]{2}{*}{ Odds ratio $(95 \% \mathrm{Cl})$} & \multicolumn{2}{|c|}{$P$ value of difference } \\
\hline & From reference & Overall \\
\hline 1.00 & - & $<0.001$ \\
\hline 0.98 (0.94 to 1.03$)$ & 0.474 & \\
\hline $0.96(0.91$ to 1.01$)$ & 0.109 & \\
\hline $0.70(0.66$ to 0.74$)$ & $<0.001$ & \\
\hline
\end{tabular}

\begin{tabular}{c} 
Laparotomy \\
Odds ratio $(95 \% \mathrm{Cl})$ \\
\cline { 2 - 2 } From reference Overall
\end{tabular}

Age (years):

\begin{tabular}{|c|c|c|c|c|c|c|}
\hline $17-54$ & 1.00 & - & \multirow[t]{4}{*}{$<0.001$} & 1.00 & - & \multirow[t]{4}{*}{$<0.001$} \\
\hline $55-69$ & 0.98 (0.94 to 1.03$)$ & 0.474 & & 0.94 (0.89 to 0.99$)$ & 0.022 & \\
\hline $70-79$ & $0.96(0.91$ to 1.01$)$ & 0.109 & & 0.93 (0.88 to 0.99$)$ & 0.013 & \\
\hline$>79$ & 0.70 (0.66 to 0.74$)$ & $<0.001$ & & 0.68 (0.63 to 0.73$)$ & $<0.001$ & \\
\hline \multicolumn{7}{|l|}{ Diagnosis: } \\
\hline Colorectal cancer & 1.00 & - & \multirow[t]{3}{*}{$<0.001$} & 1.00 & - & \multirow[t]{3}{*}{$<0.001$} \\
\hline Diverticular disease & $1.12(1.06$ to 1.18$)$ & $<0.001$ & & $1.04(0.97$ to 1.11$)$ & 0.280 & \\
\hline Other & $1.40(1.34$ to 1.46$)$ & $<0.001$ & & 1.35 (1.28 to 1.42$)$ & $<0.001$ & \\
\hline \multicolumn{7}{|l|}{ Charlson score: } \\
\hline 0 & 1.00 & - & $<0.001$ & 1.00 & - & $<0.001$ \\
\hline Female $v$ male & 0.75 (0.73 to 0.78 ) & & $<0.001$ & 0.74 (0.71 to 0.77$)$ & & $<0.001$ \\
\hline \multicolumn{7}{|l|}{ Social deprivation: } \\
\hline 1 Least deprived & 1.00 & - & \multirow[t]{5}{*}{$<0.001$} & 一 & & \\
\hline 2 & $1.00(0.95$ to 1.05$)$ & 0.973 & & - & & \\
\hline 3 & 1.06 (1.01 to 1.11$)$ & 0.032 & & - & & \\
\hline 4 & 1.09 (1.04 to 1.15$)$ & 0.001 & & - & & \\
\hline 5 Most deprived & $1.14(1.08$ to 1.20$)$ & $<0.001$ & & 一 & & \\
\hline \multicolumn{7}{|l|}{ Site of resection: } \\
\hline Year of surgery (continuous variable) & $1.03(1.03$ to 1.04$)$ & & $<0.001$ & $1.03(1.02$ to 1.04$)$ & & $<0.001$ \\
\hline
\end{tabular}


Table 6| Multiple regression analysis of 30 day mortality in hospital after colorectal resection among 246469 patients in English NHS trusts between 1 April 2000 and 31 March 2008, with reoperation on the index admission as a covariate

\begin{tabular}{|c|c|c|c|}
\hline & \multirow[b]{2}{*}{ Odds ratio $(95 \% \mathrm{Cl})$} & \multicolumn{2}{|c|}{$P$ value of difference } \\
\hline & & From reference & Overall \\
\hline \multicolumn{4}{|l|}{ Age (years): } \\
\hline $17-54$ & 1.00 & - & \multirow[t]{4}{*}{$<0.001$} \\
\hline $55-69$ & 3.17 (2.92 to 3.45$)$ & $<0.001$ & \\
\hline $70-79$ & 7.11 (6.56 to 7.70$)$ & $<0.001$ & \\
\hline$>79$ & $14.53(13.41$ to 15.75$)$ & $<0.001$ & \\
\hline \multicolumn{4}{|l|}{ Charlson morbidity score: } \\
\hline 0 & 1.00 & - & \multirow[t]{3}{*}{0.001} \\
\hline 14 & $1.62(1.53$ to 1.71$)$ & $<0.001$ & \\
\hline$\geq 5$ & $3.00(2.90$ to 3.11$)$ & $<0.001$ & \\
\hline \multicolumn{4}{|l|}{ Social deprivation (Carstairs index): } \\
\hline 1 Least deprived & 1.00 & - & \multirow[t]{5}{*}{$<0.001$} \\
\hline 2 & $1.09(1.03$ to 1.15$)$ & 0.002 & \\
\hline 3 & $1.21(1.14$ to 1.27$)$ & $<0.001$ & \\
\hline 4 & 1.31 (1.24 to 1.38$)$ & $<0.001$ & \\
\hline 5 Most deprived & $1.51(1.43$ to 1.59$)$ & $<0.001$ & \\
\hline Unclassified & 0.71 (0.34 to 1.46$)$ & 0.345 & \\
\hline Female $v$ male & 0.90 (0.87 to 0.93$)$ & $<0.001$ & \\
\hline Laparoscopy $v$ open approach & 0.56 (0.49 to 0.63$)$ & $<0.001$ & \\
\hline Emergency $v$ elective admission & 3.85 (3.70 to 3.99 ) & $<0.001$ & \\
\hline \multicolumn{4}{|l|}{ Diagnosis: } \\
\hline Cancer & 1.00 & - & \multirow[t]{4}{*}{$<0.001$} \\
\hline Inflammatory bowel disease & $1.08(0.98$ to 1.19$)$ & 0.118 & \\
\hline Diverticular disease & $1.60(1.52$ to 1.69$)$ & $<0.001$ & \\
\hline Other & 2.49 (2.39 to 2.59$)$ & $<0.001$ & \\
\hline \multicolumn{4}{|l|}{ Site of resection: } \\
\hline Right sided colectomy & 1.00 & - & \multirow[t]{4}{*}{$<0.001$} \\
\hline Left sided colectomy & $1.22(1.17$ to 1.27$)$ & $<0.001$ & \\
\hline Rectal & 0.86 (0.81 to 0.90$)$ & $<0.001$ & \\
\hline Total colectomy & $1.88(1.78$ to 1.99$)$ & $<0.001$ & \\
\hline Reoperation $v$ no reoperation & 2.68 (2.53 to 2.83 ) & $<0.001$ & \\
\hline
\end{tabular}




\section{Figures}

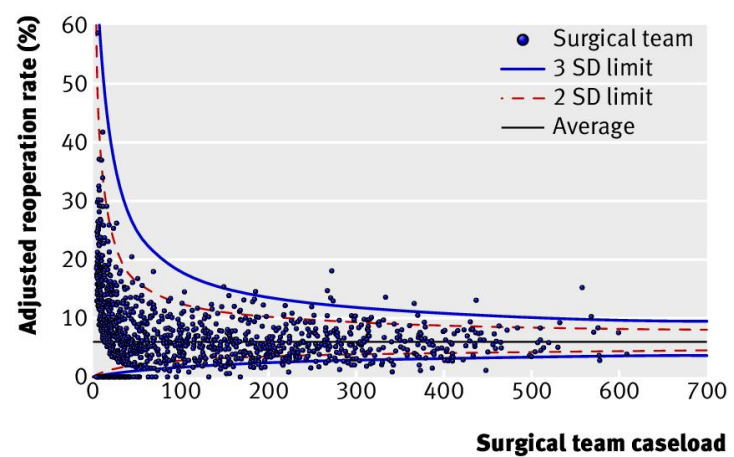

Fig 1 Funnel plot of adjusted reoperation rates for elective procedures for individual consultant teams by volume of elective surgery

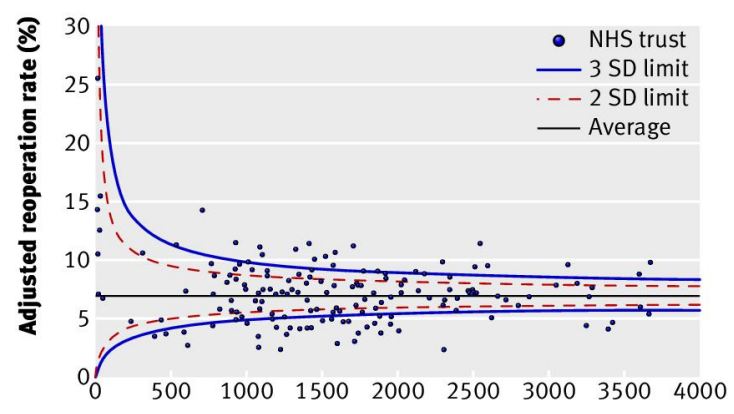

NHS trust caseload

Fig 2 Funnel plot of adjusted reoperation rates for both emergency and elective procedures for individual NHS trusts by volume 